OPEN

SUBJECT AREAS:

ENVIRONMENTAL

MICROBIOLOGY

BACTERIAL GENOMICS

Received

16 July 2014

Accepted

20 November 2014

Published

13 January 2015

Correspondence and requests for materials should be addressed to

Z.S. (shaozz@163.

com)

* These authors contributed equally to this work.

\section{Genomic and metabolic analysis of fluoranthene degradation pathway in Celeribacter indicus $\mathrm{P} 3^{\top}$}

\author{
Junwei $\mathrm{Cao}^{1,2 *}$, Qiliang Lail *, Jun Yuan' \& Zongze Shao'
}

\begin{abstract}
'State Key Laboratory Breeding Base of Marine Genetic Resources; Key Laboratory of Marine Genetic Resources, The Third Institute of State Oceanic Administration; Key Laboratory of Marine Genetic Resources of Fujian Province; Collaborative Innovation Center of Deep Sea Biology; Collaborative Innovation Center for Exploitation and Utilization of Marine Biological Resources, Xiamen 361005, China, ${ }^{2}$ School of Municipal and Environmental Engineering, Harbin Institute of Technology, Harbin 150090, China.
\end{abstract}

Celeribacter indicus $\mathrm{P} 73^{\mathrm{T}}$, isolated from deep-sea sediment from the Indian Ocean, is capable of degrading a wide range of polycyclic aromatic hydrocarbons (PAHs) and is the first fluoranthene-degrading bacterium within the family Rhodobacteraceae. Here, the complete genome sequence of strain $\mathrm{P} 73^{\mathrm{T}}$ is presented and analyzed. Besides a $4.5-\mathrm{Mb}$ circular chromosome, strain $\mathrm{P}^{7} 3^{\mathrm{T}}$ carries five plasmids, and encodes 4827 predicted protein-coding sequences. One hundred and thirty-eight genes, including 14 dioxygenase genes, were predicted to be involved in the degradation of aromatic compounds, and most of these genes are clustered in four regions. P73_0346 is the first fluoranthene 7,8-dioxygenase to be discovered and the first fluoranthene dioxygenase within the toluene/biphenyl family. The degradative genes in regions $B$ and $D$ in $\mathrm{P}^{7} 3^{\mathrm{T}}$ are absent in Celeribacter baekdonensis B30, which cannot degrade PAHs. Four intermediate metabolites [acenaphthylene-1 $(2 \mathrm{H})$-one, acenaphthenequinone, 1,2-dihydroxyacenaphthylene, and 1,8-naphthalic anhydride] of fluoranthene degradation by strain $P 73^{\mathrm{T}}$ were detected as the main intermediates, indicating that the degradation of fluoranthene in $P 73^{\mathrm{T}}$ was initiated by dioxygenation at the $\mathrm{C}-7,8$ positions. Based on the genomic and metabolitic results, we propose a $\mathrm{C}-7,8$ dioxygenation pathway in which fluoranthene is mineralized to TCA cycle intermediates.

$\mathrm{P}$ olycyclic aromatic hydrocarbons (PAHs) are ubiquitous, toxic, and persistent organic compounds in the environment. Microbial degradation studies have shown that biodegradation of PAHs is an efficient way to remove these pollutants from the environment ${ }^{1}$. Microorganisms can produce a number of catabolic enzymes and have developed different mechanisms to degrade PAHs. The degradation of PAH is usually initiated by hydroxylation, especially dioxygenation, which is catalyzed by oxygenase ${ }^{2}$. PAHs are then transformed through different peripheral pathways into a few key intermediates (such as protocatechuate, salicylate, gentisate, and catechol), which subsequently are metabolized via the central pathways ${ }^{2,3}$. Metabolic pathways have been proposed in many degraders; for example, Mycobacterium vanbaalenii PYR-1 $1^{2,4}$, Mycobacterium sp. JS14 $4^{5}$, Sinorhizobium sp. C4 $4^{6}$, Sphingomonas sp. LB126 $6^{7}$, Rhodococcus spp. ${ }^{8}$, Pasteurella sp. IFA ${ }^{9}$, Staphylococcus sp. $\mathrm{PN} / \mathrm{Y}^{10}$, Burkholderia fungorum $\mathrm{LB} 400^{11}$ and Pseudomonas sp. $\mathrm{PP} 2^{12}$, but rarely in marine bacteria. Although great advances have been made, many aspects of PAH biodegradation, especially of high-molecular-weight PAHs, remain unclear.

Fluoranthene, a non-alternant high-molecular-weight PAH, that contains a five-member ring, is structurally similar to other compounds of environmental concern, such as acenaphthylene, carbazole, fluorene, dibenzodioxin, dibenzofuran, and dibenzothiophene ${ }^{1,4}$. Therefore fluoranthene has been used as a model compound for biodegradation studies, and many bacterial fluoranthene degraders have been reported; for example, bacteria in the genera Sphingomonas ${ }^{13}$, Alcaligenes $^{14}$, Burkholderia $^{15}$, Pseudomonas $^{16}$, Mycobacterium $^{5,17,18}$ and Rhodococcus $^{19}$. However, only a few fluoranthene degraders belonging to the genera Ochrobactrum ${ }^{20}$, Novosphingobium $^{21}$, Cycloclasticus ${ }^{22}$, and Celeribacter ${ }^{23}$ have been isolated from the marine environment. Fluoranthene degradation was found to be initiated by dioxygenation at the C-1,2, C-2,3 C-7,8, and C-8,9 positions $^{4,5,9,17,18,24}$ or a possible monooxygenation to produce monohydroxyfluoranthene ${ }^{7}$. Despite these advances, gaps in our knowledge of the mechanisms of fluoranthene degradation still exist, especially for marine-sourced degraders. 
Complete genome sequencing can provide more information, including possible insights into the mechanisms of aromatic compounds degradation, and a large number of $\mathrm{PAH}$-degraders have been sequenced. For example, the Mycobacterium vanbaalenii PYR1 genome was reported with focus on the aromatic catabolic genes in the PAH pathway ${ }^{25}$. The phenanthrene-degrading bacterium Delftia sp. Cs1-4 harbors a novel genomic island, phn island, containing genes in the PAH catabolic pathway ${ }^{26}$. Comparative genomic analyses of the marine bacterium Alteromonas sp. SN2 revealed that genetic acquisitions contributed to its ability to metabolize $\mathrm{PAHs}^{27}$. The genome of Polaromonas naphthalenivorans CJ2 was reported to contain genes for at least four central pathways and numerous peripheral pathways for aromatic compound metabolism ${ }^{28}$. However, research on the mechanism of PAH degradation is far to be understood, many aspects of the metabolic pathways remain unknown.

Celeribacter indicus $\mathrm{P}^{\mathrm{T}}{ }^{\mathrm{T}}\left(=\mathrm{MCCC} 1 \mathrm{~A} 01112^{\mathrm{T}}=\mathrm{LMG} 27600^{\mathrm{T}}=\right.$ DSM $27257^{\mathrm{T}}$ ), isolated from deep-sea sediment from the Indian Ocean by enrichment of PAHs, was shown to be able to degrade a wide range of PAHs, including naphthalene, phenanthrene, dibenzothiophene, and fluoranthene ${ }^{23}$. Strain $\mathrm{P}^{\mathrm{T}}{ }^{\mathrm{T}}$ is the first fluoranthene-degrading bacterium to be found within the family Rhodobacteraceae. Here we report the complete genome sequence of $C$. indicus $\mathrm{P} 73^{\mathrm{T}}$ with the focus on the aromatic degradative genes involved in the metabolism of PAHs, and describe a possible fluoranthene degradation pathway in strain $\mathrm{P}^{2}{ }^{\mathrm{T}}$.

\section{Results}

General aspects of the $P 73^{\mathrm{T}}$ genome. The complete genome sequence of $C$. indicus $\mathrm{P}^{\mathrm{T}}{ }^{\mathrm{T}}$ was 4,969,388-bp long, comprising a circular chromosome of 4,529,105 bp and five plasmids ranging from $7053 \mathrm{bp}$ to $155,183 \mathrm{bp}$ in length (Figure 1 and Table 1). The complete genome had a $\mathrm{G}+\mathrm{C}$ content of $65.74 \mathrm{~mol} \%$, and contained 4827 predicted protein-coding sequences (CDSs) with an average length of $909 \mathrm{bp}$, giving a coding density of $88.30 \%$. Among the 4827 CDSs, $3908(80.96 \%)$ were assigned to 22 different clusters of orthologous groups (COGs) (see Supplementary Text S1 and Supplementary Data S1 for details). The chromosome encodes two sets of rRNA genes (two 5S rRNA, two 16S rRNA, and two 23S rRNA), 48 tRNA genes with 42 different anticodons that represent only 19 amino acids, and a tRNA for OTHER amino acid. No gene for tRNA-Tyr was found, although the corresponding tyrosyl-tRNA synthetase gene (P73_1712) was identified.

Thirty-seven GIs (36 in the chromosome, one in plasmid pP73C) were predicted in the genome of strain $\mathrm{P} 73^{\mathrm{T}}$ by SIGI-HMM using IslandViewer ${ }^{29}$, comprising a total of 314,694 -bp $(6.33 \%$ of the genome) and 346 predicted CDSs (see Supplementary Text S2, Supplementary Figure S1 and Supplementary Data S2 for details). Seven hundred and forty nine horizontally transferred genes (HTG) in the $P 73^{\mathrm{T}}$ genome were identified against the genomes of other bacteria in the IMG database (24 October 2013), most of which (56.6\%, 424/749) had best hits to HTG from order Rhizobiales. Genes involved in PAH degradation were found among these HTG suggesting that strain $\mathrm{P} 73^{\mathrm{T}}$ may have used gene transfer to enhance its PAH degradation ability (see Supplementary Text S3 and Supplementary Data S3 for details).

Strain $\mathrm{P} 73^{\mathrm{T}}$ can use many sugars, including D-cellobiose, D-fructose, D-trehalose, L-rhamnose, maltose, sucrose, turanose, and $\alpha$-Dglucose $^{23}$. Genes that encode the enzymes required for all the steps in the glycolysis/gluconeogenesis pathways were present, except for glucose-6-phosphatase (EC:3.1.3.9), which converts D-glucose 6phosphate to D-glucose in the gluconeogenesis pathway. In addition, strain $\mathrm{P} 73^{\mathrm{T}}$ harbors genes that encode all the enzymes needed in the pentose phosphate (PP) pathway, the Entner-Doudoroff (ED) pathway, and the tricarboxylic acid (TCA) cycle.

The principal fatty acids of strain $\mathrm{P} 73^{\mathrm{T}}$ were found to be the $\mathrm{C} 18$ unsaturated fatty acids ${ }^{23}$, which are classified as long-chain fatty acids. Unsaturated fatty acids contribute to the fluidization of membranes for adaption to low temperatures or starvation in the deep sea, and to poor aqueous solubility of aromatic hydrocarbon substrates $^{2,30}$. Fifty-three genes in fatty acid biosynthesis and metabolism pathways were identified, including two fatty acid desaturases (P73_2794 and P73_2801). In addition, two fadL long-chain fatty acid transport protein genes (P73_0184 and P73_2224) and six genes encoding the proposed fatty acid transporter (FAT) family (TC:4.C.1) of proteins were detected in the $\mathrm{P} 73^{\mathrm{T}}$ genome.

A total of 848 transport protein genes (see Supplementary Text S4 and Supplementary Data S4 for details) belonging to 102 transporter families were identified in the Transporter Classification (TC) Database (http://tcdb.org/) ${ }^{31}$. These transport protein genes made up about $17.57 \%$ of the total CDSs in the $\mathrm{P} 73^{\mathrm{T}}$ genome compared with $13.01 \%$ in the average bacterial genome in the IMG database. Many transporter genes in the $\mathrm{P} 73^{\mathrm{T}}$ genome were found to encode proteins belonging to the ATP-binding cassette (ABC) superfamily (TC:3.A.1, 371 genes) ${ }^{32,33}$, the tripartite ATP-independent periplasmic transporter (TRAP-T) family (TC:2.A.56, 96 genes) ${ }^{34}$, the major facilitator superfamily (MFS, TC:2.A.1, 25 genes) ${ }^{35}$, the tricarboxylate transporter (TTT) family (TC:2.A.80, 8 genes) ${ }^{36}$, the outer membrane protein (FadL) family (TC:1.B.9, P73_0184 and P73_2224) ${ }^{37}$, and the benzoate: $\mathrm{H}^{+}$symporter (BenE) family (TC:2.A.46, P73_3226) ${ }^{35}$, all of which have been reported to be involved in the uptake of various aromatic compounds.

The COG analysis identified 305 genes in the $\mathrm{P} 73^{\mathrm{T}}$ genome that were assigned to the transcription (K, 7.09\%) category (see Supplementary Text S5 and Supplementary Data S5 for details). Many transcriptional regulator genes in the $\mathrm{P} 73^{\mathrm{T}}$ genome were predicted to belong to the LysR-type transcriptional regulator (LTTR) family (COG0583, 53 genes) ${ }^{38,39}$, the multiple antibiotic resistance regulator (MarR) family (COG1846, 19 genes) ${ }^{39}$, the isocitrate lyase regulator (IclR) family ${ }^{40}$, the AraC, GntR, TetR, and FNR families or to two component regulatory systems, all of which have been reported to be associated with the degradation pathways of aromatic compounds ${ }^{39}$.

Plasmids. Together, the five plasmids in strain $\mathrm{P} 73^{\mathrm{T}}$ contained 438 CDSs, accounting for $9.07 \%$ of the total CDSs in the genome. The COG analysis showed that the genes in four COG functional groups (information storage and processing, cellular processes and signaling, metabolism, and poorly characterized) were distributed quite differently among the plasmids, indicating a specialized function for each plasmid (see Supplementary Text S6 and Supplementary Figure S2 for details).

Phylogenetic analysis of the plasmid partition protein (parA) and plasmid replication protein ( $r e p$ ) genes has been used previously to gain insight into the origin and evolution of plasmids ${ }^{28,41}$. Neighborjoining phylogenetic trees were constructed with the Rep (Figure 2A) and ParA (Figure 2B) protein sequences encoded by genes from the $\mathrm{P} 73^{\mathrm{T}}$ chromosome and plasmids (see Supplementary Text S6 for details). The ParA and Rep proteins encoded from the different plasmids belonged to different clades, suggesting that divergent evolution of the parA and rep genes had occurred, and confirming the important role of gene horizontal transfer, which has been reported previously ${ }^{41}$. Based on the HTG analysis, the replicative genes P73_4797 and P73_4817 were predicted to originate from Acetobacter aceti ATCC 23746 (IMG Gene ID:2516943643) and the plasmid pYAN-1 of Sphingobium yanoikuyae ATCC 51230 (JCM 7371), respectively (Supplementary Data S3), in agreement with their predicted phylogenetic positions (Figure 2A).

Genomic comparisons with closely related bacteria. C. indicus $\mathrm{P} 73^{\mathrm{T}}$ in the family Rhodobacteraceae, was found to be closely related to species in the genera Celeribacter, Pseudoruegeria, Lutimaribacter, Charonomicrobium, and Roseibacterium based on similarities in the $16 \mathrm{~S}$ rRNA gene sequences ${ }^{23}$. All the predicted 

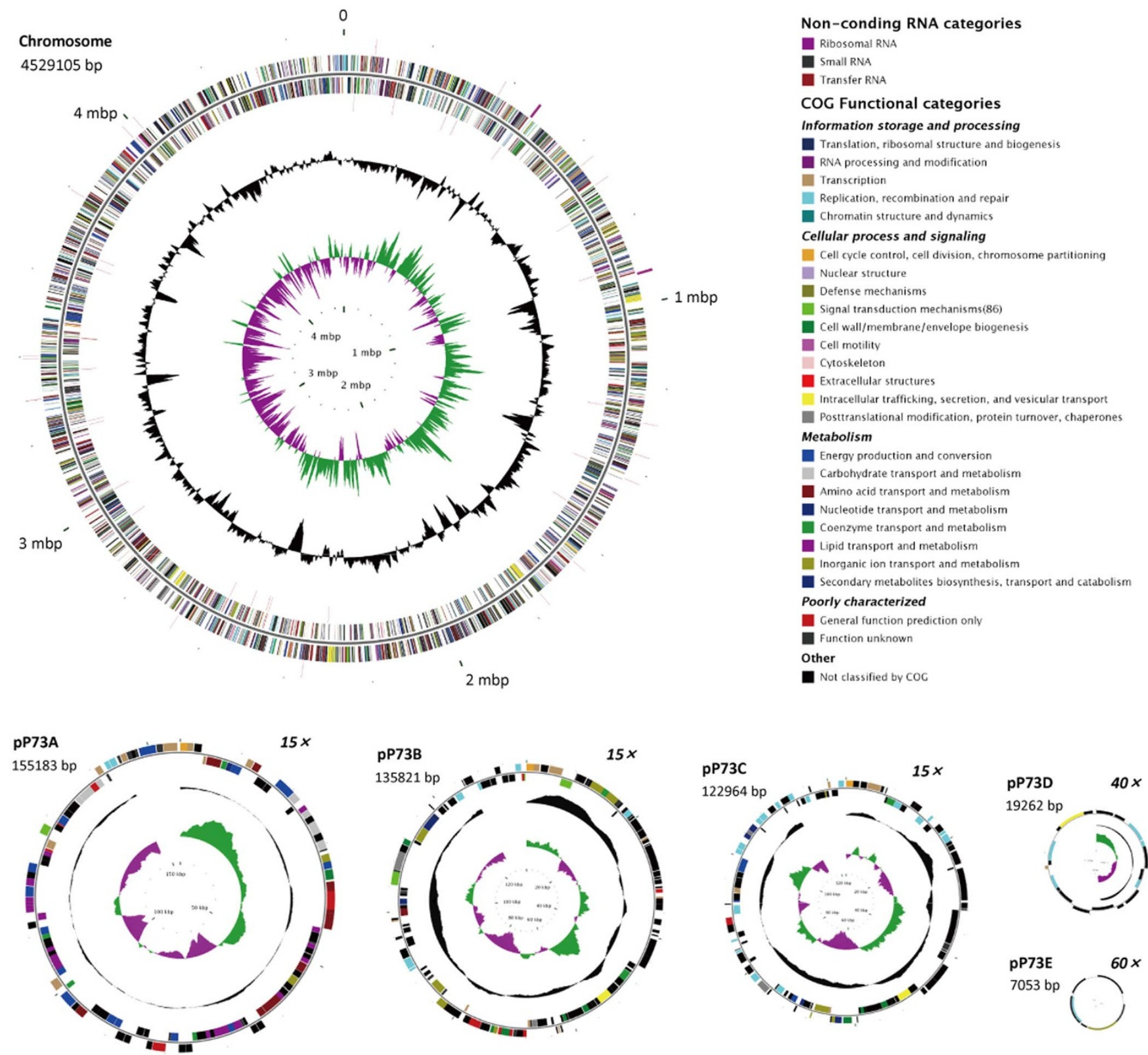

Figure 1 Circular maps of the chromosome and five plasmids of Celeribacter indicus $\mathrm{P}_{3}{ }^{\mathrm{T}}$. The chromosome $(4,529,105 \mathrm{bp})$ scale is in megabases beginning from the start of the $d n a A$ gene. Plasmids pP73A (155,183 bp), pP73B (135,821 bp), and pP73C (122,964 bp) are shown at $15 \times$ scale relative to the chromosome scale; pP73D (19,262 bp) is shown at $40 \times$ scale; and pP73E (7,053 bp) is shown at $60 \times$ scale. Rings 1 and 4 (from the outside inwards) show the forward and reverse noncoding RNAs (tRNA, rRNA, and sRNA). Rings 2 and 3 indicate all the genes in the forward and reverse strands, respectively, and the colors indicate the predicted COG categories of the genes, as shown in the figure. Ring 5 (black) represent the $\mathrm{G}+\mathrm{C}$ content (higher values outward), and ring 6 shows the $G+C$ skew $[(G-C) /(G+C)$, where green indicates values $>0$, and purple indicates values $<0]$.

proteins from strain $\mathrm{P} 73^{\mathrm{T}}$ were compared against the NCBI nonredundant protein sequence database (nr, 29 May 2013) to estimate the taxonomic distribution of the proteome. The results showed that most of the proteins encoded by the chromosomal genes of stain $\mathrm{P} 73^{\mathrm{T}}$ were closely related to proteins from species in genera Celeribacter (2096, 47.76\%), Paracoccus (133, 3.03\%), Oceanicola (123, 2.80\%), Rhizobium (122, 2.78\%), Citreicella (114, $2.60 \%$ ), and Rhodobacter (106, 2.42\%) (Figure 3), and the greatest overlap was between the proteomes of strain $\mathrm{P}^{4} 3^{\mathrm{T}}$ and Celeribacter baekdonensis $\mathrm{B} 30$. The MUMmer alignments ${ }^{42}$ of the strain $\mathrm{P} 73^{\mathrm{T}}$ genome with the whole genome sequences of other closely related bacteria also showed that $\mathrm{P} 73^{\mathrm{T}}$ was closest to C. baekdonensis $\mathrm{B} 30$, although the genomes of these two strains revealed extensive chromosomal rearrangements (Supplementary Figure S3). However, the taxonomic distributions of the five plasmid proteomes of strain $\mathrm{P} 3^{\mathrm{T}}$ were different from that of the chromosome, suggesting the chromosome and the plasmids may have had potentially different origins. The major proteins of pP73A closely matched proteins in genera Chelativorans $(18,13.33 \%)$ and Celeribacter $(15,11.11 \%)$; for $\mathrm{pP} 73 \mathrm{~B}$ they matched Roseovarius $(41,28.67 \%)$ and Celeribacter (23, 16.08\%); for pP73C, they matched Celeribacter $(32,25 \%)$ and Maritimibacter $(25,19.53 \%)$; for pP73D, they matched Oceanicola (4, 19.05\%); and for pP73E, they matched Sulfitobacter (3, $27.27 \%)$.

Bioavailability of PAHs. Aromatic compounds, especially PAHs, are hydrophobic and insoluble in water. Biosurfactants, including glycolipids, lipopeptides and lipoproteins, phospholipids, and fatty 
Table 1 | General features of the complete genome sequence of $C$. indicus P73 ${ }^{\top}$

\begin{tabular}{|c|c|c|c|c|c|c|}
\hline Content & Chromosome & \multicolumn{5}{|c|}{ Plasmids } \\
\hline Size (bp) & 4529105 & 155183 & 135821 & 122964 & 19262 & 7053 \\
\hline $\mathrm{CDS}^{a}$ number & 4389 & 135 & 143 & 128 & 21 & 11 \\
\hline Average CDS size (bp) & 914 & 1063 & 739 & 813 & 792 & 640 \\
\hline Coding density (\%) & 88.35 & 92.37 & 84.46 & 84.15 & 85.63 & 82.60 \\
\hline rRNA operon (23S, $16 \mathrm{~S}$ and 5S) & 2 & 0 & 0 & 0 & 0 & 0 \\
\hline sRNA & 2 & 0 & 0 & 0 & 0 & 0 \\
\hline GenBank accession & СР004393 & СР004394 & CP004395 & CP004396 & СР004397 & CP004398 \\
\hline
\end{tabular}

acids, can emulsify and solubilize hydrocarbons to promote the bioavailability of substrates ${ }^{43}$. Previous studies have shown that strain $\mathrm{P} 73^{\mathrm{T}}$ contained glycolipids, two phospholipids, phosphatidylglycerol, aminolipid, and one unknown lipid ${ }^{23}$. Some genes associated with the synthesis of lipids were found in the $P 73^{\mathrm{T}}$ genome: for example, 1-acylglycerol-3-phosphate $O$-acyltransferase gene plsC (P73_2315 and P73_4246); phosphatidate cytidylyltransferase gene $c d s A$ (P73_2618); CDP-diacylglycerol glycerol-3phosphate 3-phosphatidyltransferase gene pgsA (P73_4294); glycerol-3-phosphate acyltransferase gene plsX (P73_2678); and glycerol-3-phosphate acyltransferase gene plsY (P73_4283) ${ }^{44}$. Other genes involved in lipid transport and metabolism were identified based on the COG analysis (Supplementary Data S6).

Chemotaxis and cell motility can actively increase the bioavailability of $\mathrm{PAHs}^{45,46}$. Many genes for flagella assembly, cell motility, and chemotaxis were identified based on the GOG and 'KEGG Orthology (KO) terms' analyses available on the IMG server ${ }^{42}$; they included genes predicted to encode flagellin, flagellar motor protein, and the chemotaxis complex proteins CheY, CheD, CheR, CheW, CheA, CheB, McpH, and McpA (Supplementary Data S7). However, as reported previously, strain $\mathrm{P} 73^{\mathrm{T}}$ was non-motile and no flagella were observed $^{23}$. Flagellum assembly is a complex process in which many genes are known to be involved ${ }^{47}$. Compared with a motile bacterium Alteromonas taeanensis SN2 ${ }^{27}, \mathrm{P} 73^{\mathrm{T}}$ lacked genes that encode the flagellar proteins FliO, FliJ, FlgM, FliD, and FliS. As reported previously, both FliD and FliS are essential elements in the assembly of functional flagella ${ }^{47,48}$; FlgM and FliA are part of a complex regulatory network that controls flagellum number ${ }^{49}$; and FliO, FliJ, and FlhA play roles in the energy coupling mechanism for bacterial flagellar protein export $\mathrm{t}^{50}$.

Degradation of PAHs. $\mathrm{P} 73^{\mathrm{T}}$ is capable of degrading a wide range of aromatic compounds including $\mathrm{PAHs}^{23}$. A total of 138 genes in the $\mathrm{P} 3^{\mathrm{T}}$ genome were predicted to be involved in the metabolism of aromatic hydrocarbons. Most of the predicted catabolic genes were located in four regions of the genome: region A, position 168707176856 bp (P73_0169-P73_0177, 8150 bp); region B, position 331325-381010 bp (P73_0326-P73_0372, 49686 bp); region C, position 828348-837837 bp (P73_0835-P73_0846, 9490 bp); and region D, position 2990411-2998597 bp (P73_2960-P73_2968, $8187 \mathrm{bp}$ ) (Supplementary Data S8). Other genes involved in the metabolism of aromatic hydrocarbons were found dispersed all over the genome.

Within the 49.7-kb region $\mathrm{B}$, genes that were involved in the peripheral pathway for PAH degradation were identified (Figure 4). P73_0346 (biphenyl 2,3-dioxygenase subunit alpha), P73_0347 (biphenyl 2,3-dioxygenase subunit beta), P73_0348 (dioxygenase ferredoxin subunit), and P73_0354 (ferredoxin-NAD ${ }^{+}$reductase) were predicted to encode the three components of an aromatic-ringhydroxylating dioxygenase. Downstream genes P73_0349 (2,3-dihydroxy-2,3-dihydrophenylpropionate dehydrogenase), P73_0353 (catechol 2,3-dioxygenase), P73_0352 (2-hydroxychromene-2carboxylate isomerase), P73_0351 (trans-o-hydroxybenzylidenepyruvate hydratase-aldolase), and P73_0350 (dehydrogenase PhnF), were proposed to be responsible for the next several steps of $\mathrm{PAH}$ ring-hydroxylation (Figure 5). Another downstream gene P73_0355, encoding an OmpW family protein (COG3047), which was reported to be a receptor of colicin $S 4^{51}$, may play a role in the sensing of aromatic compounds. Genes P73_0329 (gentisate 1,2-dioxygenase), P73_0331 (maleylacetoacetate isomerase), and P73_0330 (fumarylpyruvate hydrolase) involved in the homogentisate ring-cleavage pathway were also found in region B (Figure 5, homogentisate pathway).

Two tRNA genes (tRNA-Lys and tRNA-Arg), suggested to be common sites for the integration of foreign sequences ${ }^{52}$, were found flanking each end of region $\mathrm{B}$, and several putative transposases and integrases were encoded adjacent to the two tRNA genes. Several horizontally transferred genes (P73_0329-0341) likely involved in PAHs degradation were identified within region B (Supplementary Data S3). These observations suggested that the $\mathrm{P} 73^{\mathrm{T}}$ genome might have gained region $\mathrm{B}$, which contained the $\mathrm{PAH}$-degrading genes, via lateral gene transfer.

Based on the sequence similarities among dioxygenase alpha subunit genes, two related $\mathrm{PAH}$-degrading gene clusters from $P$. naphthalenivorans CJ2 $2^{28}$ and Polymorphum gilvum SL003B-26A1 ${ }^{46}$ were selected for comparison with the related cluster from the genome of strain $\mathrm{P} 73^{\mathrm{T}}$. The organization of gene clusters involved in PAHs catabolism of strains $\mathrm{P}^{\mathrm{T}}{ }^{\mathrm{T}}$ and SL003B-26A1 were almost identical, with only a minor gene rearrangement, while extensive rearrangements were found in the corresponding gene clusters in strains $\mathrm{P} 73^{\mathrm{T}}$ and CJ2, with the absence of the dehydrogenase PhnF, trans-o-hydroxybenzylidenepyruvate hydratase-aldolase, and 2hydroxychromene-2-carboxylate isomerase genes in the gene cluster from strain CJ2.

Phthalate has been reported as a common metabolic intermediate during $\mathrm{PAH}$ metabolism ${ }^{2}$. Region $\mathrm{D}$ contained genes predicted to be related to phthalate degradation (Figure 5), including P73_2964 (4,5-dihydroxyphthalate decarboxylase), P73_2965 (oxidoreductase domain-containing protein), P73_2966 (ferredoxin), and P73_2968 (phthalate 4,5-dioxygenase), which convert phthalate to another central metabolite, protocatechuate. The gene cluster for protocatechuate degradation via the $\beta$-ketoadipate pathway was located in region $\mathrm{C}$ with a 4 -hydroxybenzoate 3 -monooxygenase gene, which transforms 4-hydroxybenzoate to protocatechuate, included in the cluster (Figure 5). Three sets of genes involved in the gentisate ringcleavage pathway were found in the $\mathrm{P} 73^{\mathrm{T}}$ genome (Figure 5): 

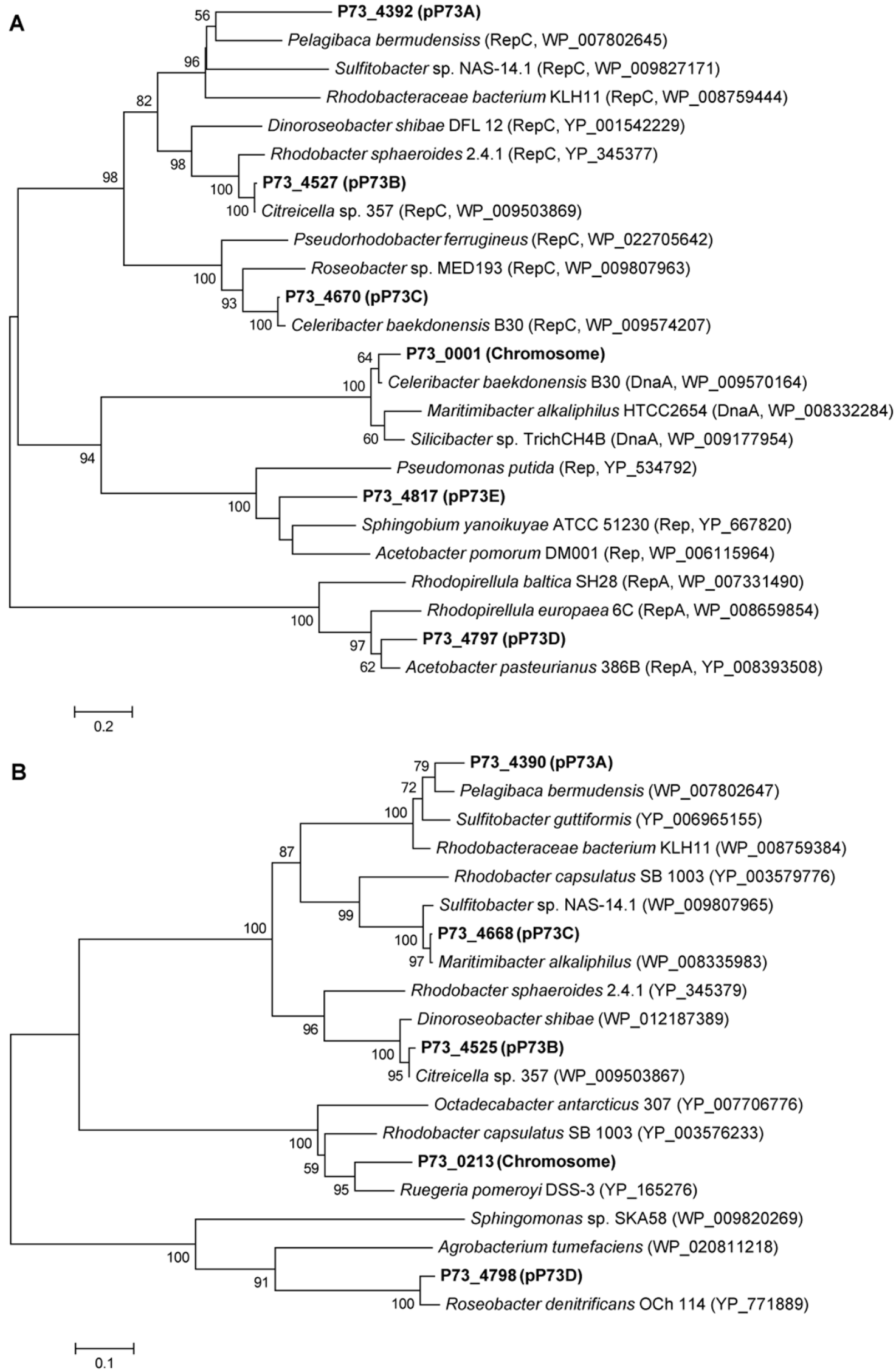

Figure $2 \mid$ Neighbor-joining phylogenetic trees constructed with replication protein (Rep) (A) and partition protein (ParA) (B) sequences from strain $\mathrm{P}^{7} 3^{\mathrm{T}}$ chromosome and plasmids. Bootstrap values $>50 \%$ (expressed as percentages of 1000 replications) are shown at branch points. 


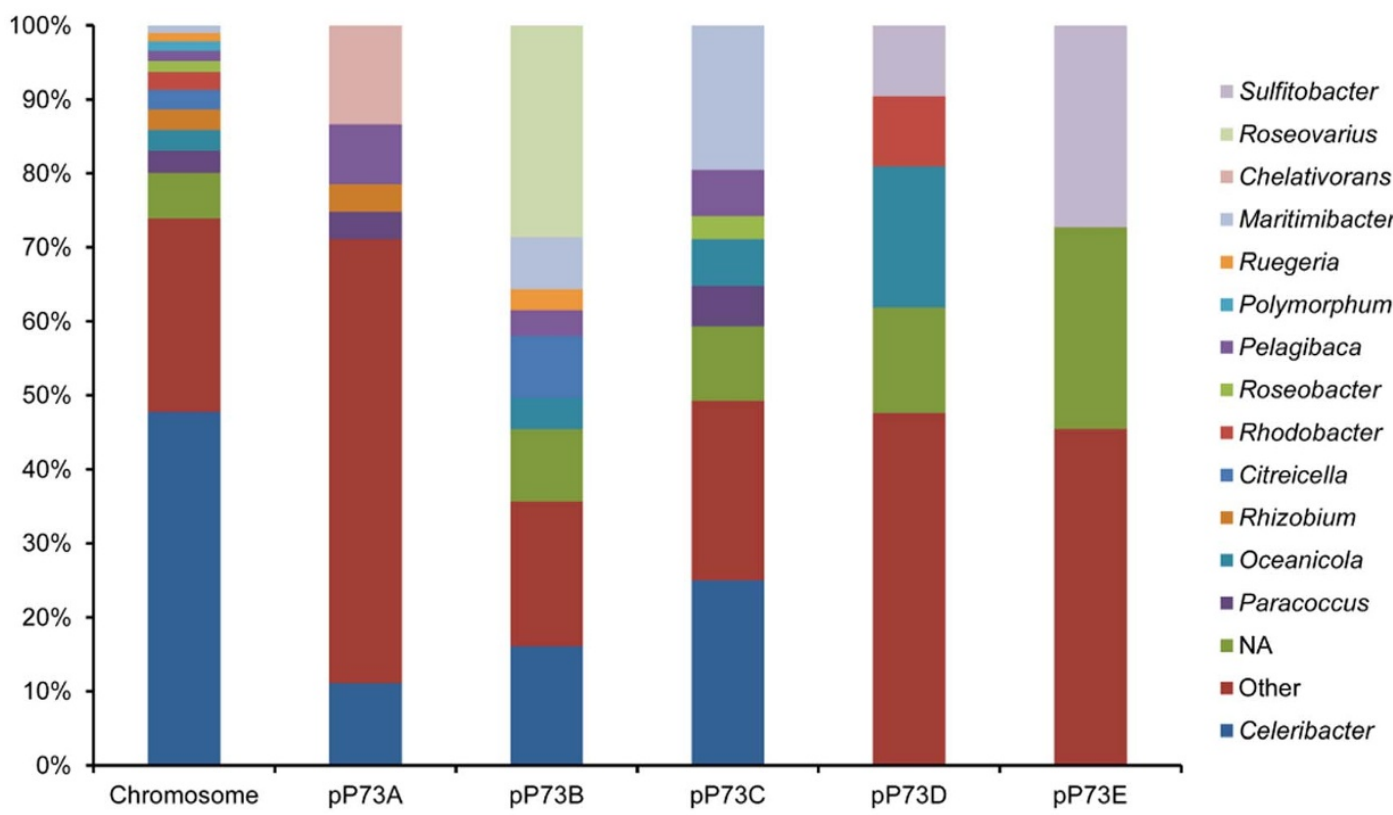

Figure $3 \mid$ Taxonomic distribution of the $C$. indicus $P 73^{\mathrm{T}}$ proteome in the chromosome and plasmids. NA indicates the proteins without matches in the nr database.

P73_0175 (gentisate 1,2-dioxygenase), P73_0176 (maleylacetoacetate isomerase), and P73_0177 (fumarylpyruvate hydrolase) in region A; P73_1454 (gentisate 1,2-dioxygenase), P73_1455 (maleylacetoacetate isomerase), and P73_1456 (fumarylpyruvate hydrolase) adjacent to a salicylate hydroxylase gene (P73_1457) in the chromosome; and, P73_4775 (gentisate 1,2-dioxygenase), P73_4774 (maleylacetoacetate isomerase), and P73_4773 (fumarylpyruvate hydrolase) in plasmid pP73C.

Many other genes were predicted to encode other enzymes including aromatic-ring-hydroxylating dioxygenase, ferredoxin reductase, ferredoxin, hydroxylase, decarboxylase, cytochrome P450, monooxygenase, dehydrogenase, hydratase, thiolase, and racemase (Supplementary Data S8). These genes, often clustered with other catabolic genes or were distributed all over the genome, may also enhance the catabolic ability of strain $\mathrm{P} 73^{\mathrm{T}}$.
Several transporter genes were found in the vicinity of aromatic catabolic genes. For instance, within region $\mathrm{B}$, transporter genes P73_0342, P73_0343, and P73_0344 were adjacent to ring-hydroxylating dioxygenase genes (P73_0346 and P73_0347). P73_2224 was predicted to encode an aromatic hydrocarbon degradation membrane protein belonging to the outer membrane transport protein (OMPP1/FadL/TodX) family ${ }^{53}$, and two transmembrane protein genes (P73_2223 and P73_2225) were located flanking P73_2224. In region D, an EamA-like transporter gene (P73_2962), which belonged to the drug/metabolite transporter family, was found adjacent to the phthalate degradative genes. P73_3226 encoded a benzoate membrane transport protein (BenE), which may transport benzoate-like aromatic compounds.

At the regulation level, several LTTR family transcriptional regulators were found adjacent to aromatic catabolic genes in the gen-

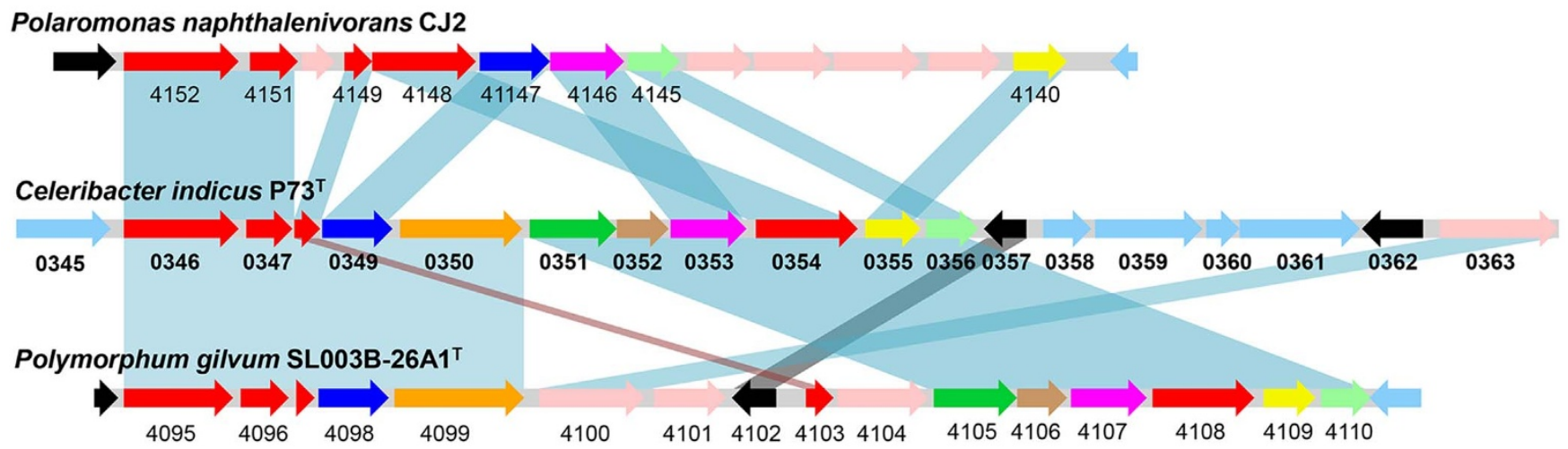

2000 4000 6000

8000

10000

12000

16000

18000

Figure 4 | Organization of the gene cluster involved in PAHs catabolism in the P73 ${ }^{\mathrm{T}}$ genome. For comparison, orthologous genes from

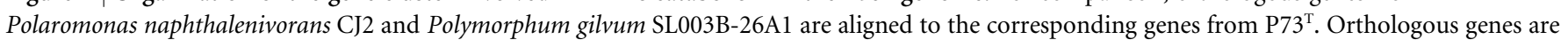
connected by shaded boxes. Annotation data for genes P73_0346-0357 from strain P73 ${ }^{\mathrm{T}}$ are provided in (Supplementary Data S9). The CJ2 genes

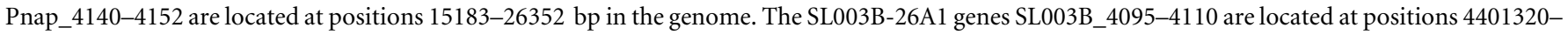
4416076 bp in the genome. 


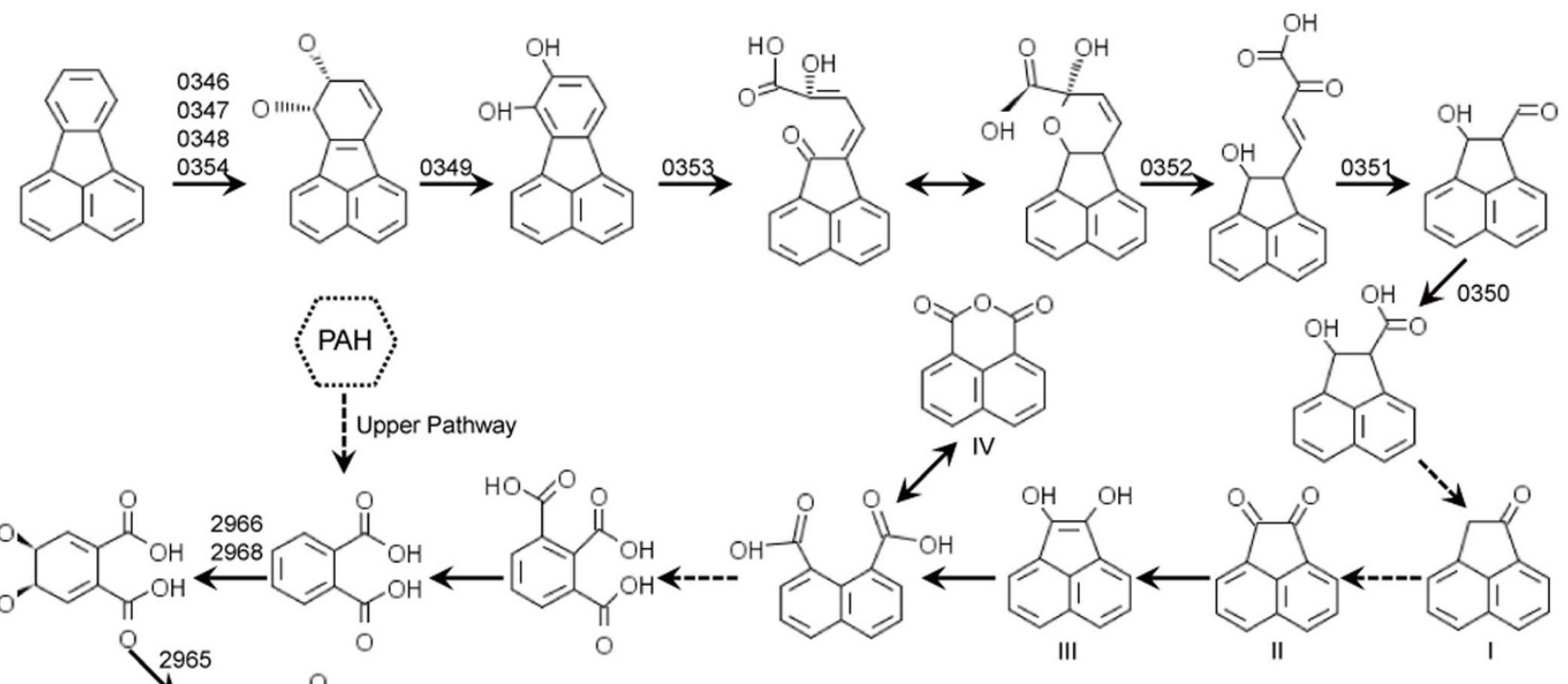<smiles>CCCCOc1cc(C(=O)O)c(C(=O)O)cc1OC</smiles><smiles>O=C(O)CCCC(=O)CC(=O)O</smiles>

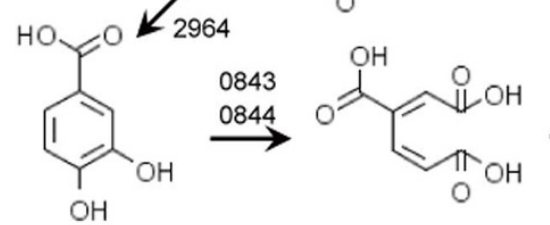

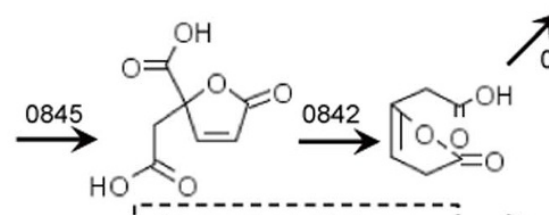
841

0<smiles>O=C(O)CCC(=O)CC(=O)SOCCO</smiles>
KGene 1

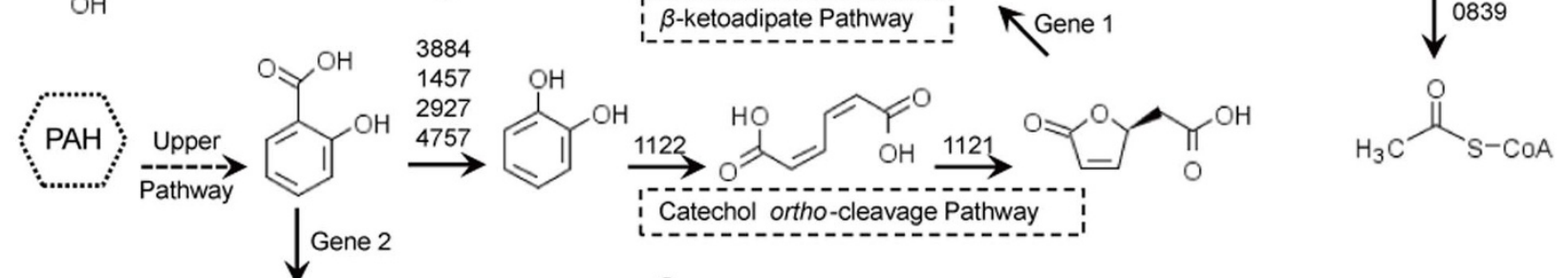

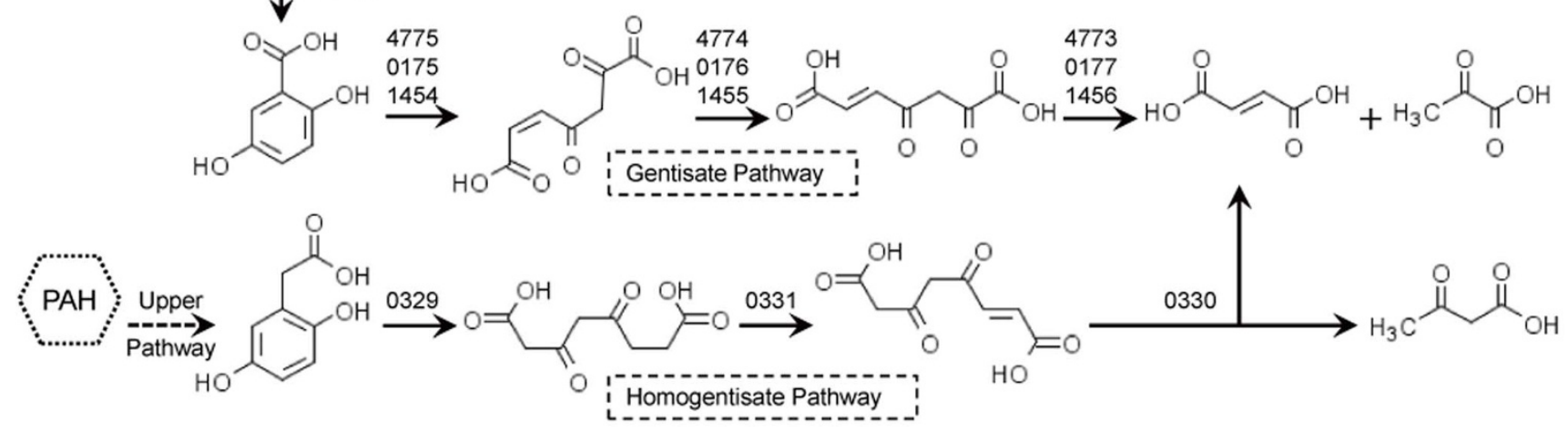

Figure $5 \mid$ Proposed pathways for the degradation of PAHs in strain $\mathrm{P}^{\mathrm{T}}{ }^{\mathrm{T}}$. I to IV indicate the metabolites detected from the fluoranthene degradation experiment. Dashed arrows indicate two or more successive reactions. The numbers above the arrows represent the gene loci in the P73 $3^{\mathrm{T}}$ genome (Supplementary Data S8). No closely related homologues were found for Gene 1 (muconolactone delta-isomerase) and Gene 2 (salicylate 5-hydroxylase) in the genome.

ome, including P73_0332 regulating the homogentisate catabolic genes, P73_0840 regulating the $\beta$-ketoadipate pathway for protocatechuate degradation, and P73_1052 regulating the aromaticring-hydroxylating dioxygenase gene (P73_1053). In addition, three MarR family transcriptional regulator genes (P73_0337, P73_0357, and P73_2961) were predicted to be involved in aromatic compounds degradation, and P73_0836 was predicted to encode the $\beta$-ketoadipate pathway transcription regulator (PcaR), which regulates the $\beta$-ketoadipate pathway for protocatechuate degradation ${ }^{39}$.
Gene knockout. P73_0346, which was located in the PAH-degrading gene cluster, was predicted to encode the aromatic-ring-hydroxylating dioxygenase alpha subunit. When this gene was disrupted by deletion with a kan cassette inserted, we found that the resulting mutant $\Delta$ P73_0346::kan was unable to use fluoranthene and naphthalene, or was defective in degrading biphenyl, phenanthrene and dibenzothiophene. These results demonstrated that P73_0346 encoded the dioxygenase subunit alpha responsible for the dioxygenation of fluoranthene, naphthalene, biphenyl, phenanthrene, and dibenzothiophene (Figure 5). 
Dioxygenases. The metabolism of PAHs begins with ring hydroxylation, which is the most difficult catalytic step and usually catalyzed by ring-hydroxylating dioxygenases (RHDs). RHD is a multicomponent enzyme system that consists of a terminal oxygenase(s) and an electron transfer component $(s)^{25}$. Multiple paralogs to ring-hydroxylating dioxygenase subunit alpha (P73_0346, P73_1053, P73_2151, P73_2875, P73_2968, and P73_4415), ringhydroxylating dioxygenase subunit beta (P73_0347 and P73_2150), ferredoxin (P73_0348, P73_1051, P73_2167, P73_2169, P73_2960, P73_3499, and P73_4762), and ferredoxin reductase (P73_0335, P73_0354, P73_0554, P73_1054, P73_2874, P73_4416, and P73_4758) were found in the P73 ${ }^{\mathrm{T}}$ genome. Because RHD subunit alpha plays a major role in determining substrate specificity, RHD alpha subunit has been used in phylogenetic analysis to classify $\mathrm{RHDs}^{54}$. The phylogenetic tree of RHD alpha subunits from P73 ${ }^{\mathrm{T}}$ and other representative species is shown in Figure 6. The toluene/ biphenyl family (group IV) comprises three-component enzymes from pathways for the degradation of chlorobenzenes, alkylbenzenes, benzene, and biphenyl ${ }^{54}$. P73_0346, which could catalyze the dioxygenation of fluoranthene, naphthalene, biphenyl, phenanthrene, and dibenzothiophene, also clustered with group IV. P73_2151 may catalyze the dihydroxylation or deamination of aniline, because it was grouped with the benzoate dioxygenase family (group II), which has been reported previously to perform similar functions ${ }^{54}$. P73_1053, P73_2875, and P73_2968, which comprised two components (an $\alpha_{n}$ oxygenase component and a reductase component), fell into the phthalate $\left(\alpha_{n}\right)$ family (group I) and were predicted to be involved in the degradation of aromatic compounds structurally similar to phthalate. The protein encoded by the plasmid gene P73_4415 clustered with some phenylpropionate dioxygenases, which may form a new family (group VII). No closely related homologues were found in the $\mathrm{P} 73^{\mathrm{T}}$ genome for the naphthalene family (group III), the $\mathrm{Gram}^{+} \mathrm{PAH} /$ phthalate family (group V), or the salicylate dioxygenases family (group VI).

Several dioxygenases that can transform fluoranthene have been reported previously. For example, ArhA1 [GenBank:BAD34447] from Sphingomonas sp. A4 $4^{55}$, PhnAla [GenBank:CAG17576] from Sphingomonas sp. CHY-1 ${ }^{56}$, and PhnA1f [GenBank:ABW37061] from Sphingomonas sp. LH128 ${ }^{57}$, all of which belong to the naphthalene family (group III), can convert fluoranthene to the corresponding dihydrodiol or monohydroxylated products. NidA3 [GenBank: ABM11369] from Mycobacterium vanbaalenii PYR-1 ${ }^{2}$, and PhdA [GenBank:ABK27720] from Mycobacterium sp. SNP11 ${ }^{58}$, which were clustered with $\mathrm{Gram}^{+} \mathrm{PAH} /$ phthalate family (group V) dioxygenases, can oxidize fluoranthene. Fluoranthene 2,3-dioxygenase CarAa [GenBank:BAA21728] from Pseudomonas sp. CA10 ${ }^{59}$ was grouped with the phthalate $\left(\alpha_{n}\right)$ family (group I), while Mvan 0533 [GenBank:ABM11377] and Mvan_0539 [GenBank:ABM11383] from Mycobacterium vanbaalenii PYR-12 ${ }^{2}$, FlnA1 [GenBank:ABV68886] from Shpingomonas sp. LB126 ${ }^{60}$, and IdoA (GenBank:AF474963) from Pseudomonas alcaligenes PA-10 ${ }^{61}$, all of which were also reported to oxidize fluoranthene, did not fall into any dioxygenase family group. To our knowledge, P73_0346 is the first fluoranthene dioxygenase to be identified within the RHD alpha subunit toluene/ biphenyl family (group IV).

Ring-cleaving dioxygenases catalyze critical dearomatization steps in the PAH degradation pathway ${ }^{25}$. Nine genes in the genome of $\mathrm{P} 73^{\mathrm{T}}$ were predicted to encode different ring-cleaving dioxygenases, namely, gentisate 1,2-dioxygenase (P73_0175, P73_1454, and P73_ 4775), homogentisate 1,2-dioxygenase (P73_0329), catechol 2,3dioxygenase (P73_0353), extradiol ring-cleavage dioxygenase III subunit B (P73_0507), protocatechuate 3,4-dioxygenase (P73_0843 and P73_0844), and catechol 1,2-dioxygenase (P73_1122).

Fluoranthene degradation. It has been reported previously that strain $\mathrm{P}^{\mathrm{T}}$ can degrade fluoranthene, a high-molecular-weight
$\mathrm{PAH}$ that has been used as a model $\mathrm{PAH}$ for biodegradation studies. Growing strain $\mathrm{P} 73^{\mathrm{T}}$ with fluoranthene resulted in the accumulation of a brown compound that had a maximal absorbance at $225 \mathrm{~nm}$. Four major metabolites were confirmed during fluoranthene degradation using gas chromatography-mass spectrometry (GC-MS): acenaphthylene-1(2H)-one (I), acenaphthenequinone (II), 1,2-dihydroxyacenaphthylene (III) and 1,8-naphthalic anhydride (IV) (Supplementary Figures S4-S7), indicating that strain $\mathrm{P} 3^{\mathrm{T}}$ metabolized fluoranthene through the C-7,8 dioxygenation pathway. Indeed, it has been suggested previously that 1,8-naphthalic anhydride (IV) is formed by the thermal decomposition of naphthalene-1, 8-dicarboxylic acid ${ }^{4}$.

The C-7,8 dioxygenation pathway for fluoranthene degradation was proposed initially in Alcaligenes denitrificans $\mathrm{WW}^{24}$, Mycobacterium vanbaalenii PYR-1 $1^{4}$, and Mycobacterium sp. AP1 $1^{18}$. Based on the genomic analysis and the metabolic data in this study, and on studies reported previously ${ }^{2,4,5,18}$, here we propose metabolic pathways for fluoranthene and assign the most probable genes to each enzymatic reaction in the pathways (Figure 5). Firstly, fluoranthene is dioxygenated at the C-7,8 positions to form fluoranthene cis-7,8-dihydrodiol, which is then catalyzed by an RHD encoded by P73_0346, P73_0347, P73_0348, and P73_0354. The resultant fluoranthene cis-7,8-dihydrodiol is then dehydrogenated by dihydrodiol dehydrogenase (P73_0349) to produce 7,8-dihydroxyfluoranthene, which is subjected to extradiol ring rupture by an extradiol-type ringcleavage dioxygenase (P73_0353) to form $(2 Z, 4 Z)$-2-hydroxy-4-(2oxoacenaphthylen-1(2H)-ylidene)but-2-enoic acid ${ }^{4}$. Subsequently, a ketal bond is formed automatically and the resulted cis isomer is transformed to (E)-4-(2-hydroxy-1,2-dihydroacenaphthylen-1-yl)2-oxobut-3-enoic acid by an isomerase (P73_0352) ${ }^{62}$. The next step is catalyzed by hydratase-aldolase (P73_0351), which releases a pyruvate to produce 2-hydroxy-1,2-dihydroacenaphthylene-1carbaldehyde, the aldehyde group of which is then oxidized to a carboxyl group ${ }^{63}$. Next, acenaphthylene-1(2H)-one (I) and acenaphthenequinone (II) are formed through two or more successive reactions. Acenaphthenequinone (II) can be reduced to 1,2-dihydroxyacenaphthylene (III), after which the central metabolite naphthalene-1, 8-dicarboxylic acid, which can be decomposed thermally to 1,8-naphthalic anhydride (IV), is formed ${ }^{4}$. Further mineralization produces 1,2,3-benzenetricarboxylic acid, phthalate, and protocatechuate, which are then metabolized through the $\beta$ ketoadipate pathway mentioned above (Figure 5).

The gentisate ring-cleavage pathway ${ }^{64}$, catechol ortho ring-cleavage pathway ${ }^{65}$, and homogentisate ring-cleavage pathway ${ }^{66}$ have also been reported to be involved in the central pathways for PAHs shown in Figure 5. All the genes involved in these central pathways were found in the genome of $\mathrm{P} 73^{\mathrm{T}}$, except for genes that encode muconolactone D-isomerase (Figure 5, Gene 1) and salicylate 5-hydroxylase (Figure 5, Gene 2).

Comparison of strain $\mathrm{P}^{\mathrm{T}}{ }^{\mathrm{T}}$ with Celeribacter baekdonensis $\mathrm{B} 30$. Strain B30 was isolated from deep-sea sediment of the Arctic Ocean $\left(\mathrm{W} 170^{\circ} 29.31^{\prime}, \mathrm{N}^{\circ} 7^{\circ} 04.27^{\prime}\right)$ at a water depth of $4000 \mathrm{~m}$ by our group. It was named Celeribacter baekdonensis based on the 16S rRNA gene sequence, which shared $99.79 \%$ similarity with that of Celeribacter baekdonensis $\mathrm{L}-6^{\mathrm{T} 67}$. The draft $\mathrm{B} 30$ genome sequence is available in GenBank (Accession: AMRK00000000). The PAH degradation test showed that strain B30 was unable to degrade naphthalene, phenanthrene, pyrene, or fluoranthene (unpublished observations).

Based on the COG analysis of the two Celeribacter genomes, we found that compared with strain B30, genes involved in amino acid transport and metabolism (E, 10.34\%) were less abundant in strain $\mathrm{P}^{\mathrm{T}}{ }^{\mathrm{T}}$, while genes involved in inorganic ion transport and metabolism $(\mathrm{P}, 9.19 \%)$, and replication, recombination and repair $(\mathrm{L}, 6.42 \%)$ $(12.53 \%, 6.31 \%$ and $4.06 \%$, respectively) were more abundant. The abundances of genes in others COGs were similar in the two strains. 


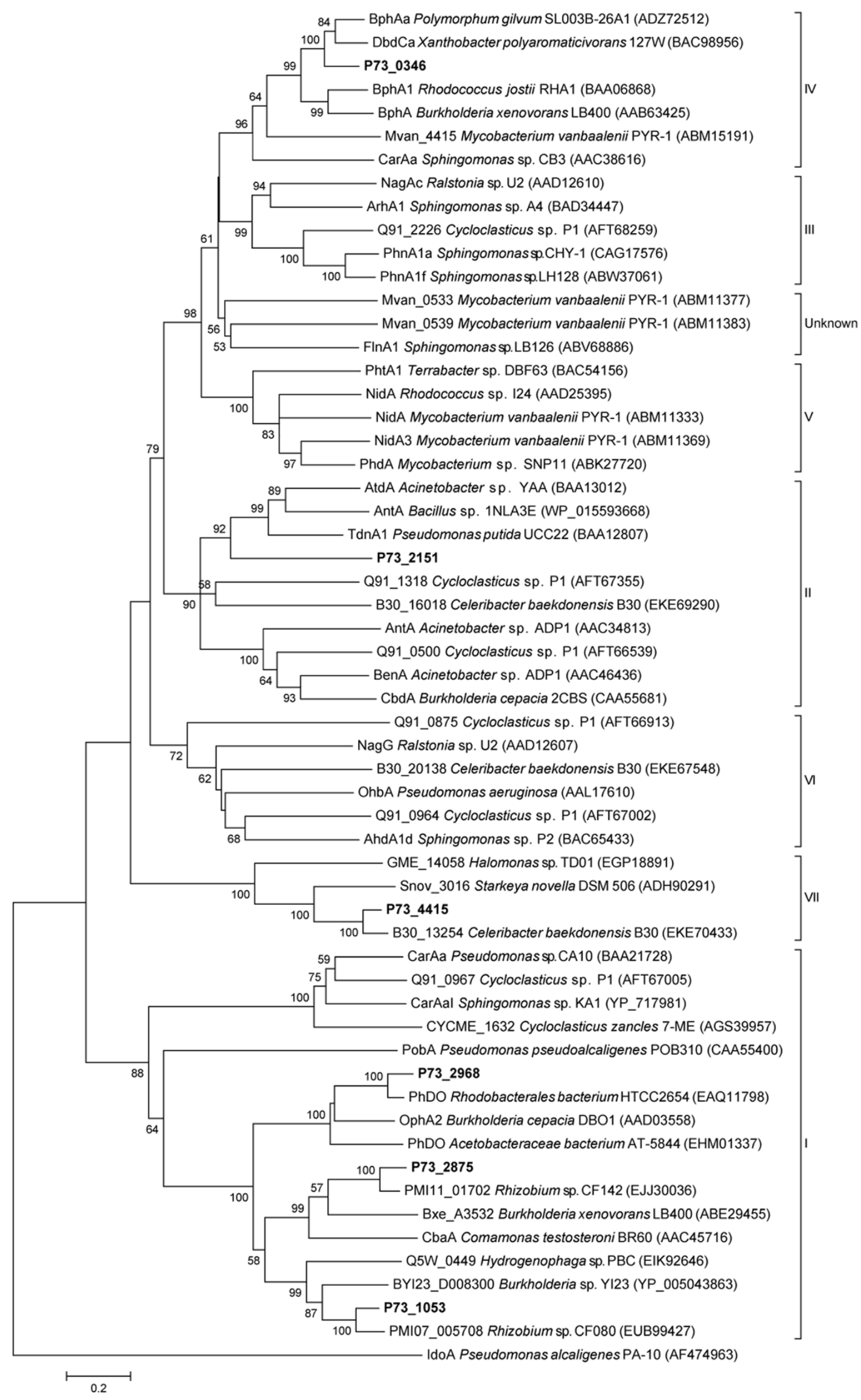

Figure $6 \mid$ Phylogenetic tree constructed using the sequences of alpha subunits of aromatic ring hydroxylating dioxygenases. The P73 ${ }^{\mathrm{T}}$ proteins are shown in bold. Bootstrap values $>50 \%$ (expressed as the percentages of 1000 replications) are shown at the branch points. 
The IMG 'Phylogenetic Profiler for Single Genes' was used to find genes in the $\mathrm{P} 73^{\mathrm{T}}$ genome that had no homologs in the $\mathrm{B} 30$ genome. A total of 1484 genes in $\mathrm{P} 73^{\mathrm{T}}$ with no homologs in $\mathrm{B} 30$ were detected (Supplementary Data S9). Interestingly, almost all the genes in regions $\mathrm{B}$ and $\mathrm{D}$ of the $\mathrm{P} 73^{\mathrm{T}}$ genome-which are responsible for PAH degradation, especially the metabolism of fluoranthene-were absent in the B30 genome. Only three RHDs were identified in the B30 genome; their phylogenetic positions are shown in Figure 5. The B30 genome had no homologues for the dioxygenases encoded by P73_0346, P73_0153, P73_2875, and P73_2968, which were predicted to be involved in the metabolism of PAHs in strain $\mathrm{P}^{2} 3^{\mathrm{T}}$.

\section{Discussion}

Our analyses of the complete genome of C. indicus $\mathrm{P}^{\mathrm{T}}{ }^{\mathrm{T}}$ have expanded the knowledge of the mechanisms used to metabolize $\mathrm{PAHs}$ in this bacterium. The $\mathrm{P} 73^{\mathrm{T}}$ genome contains 138 candidate genes that may be involved in the metabolism of aromatic compounds, including genes that encode six ring hydroxylating dioxygenases, eight ring cleaving dioxygenases, other catabolic enzymes, transcriptional regulators, and transporters in the degradation pathways. We found that genetic acquisitions via lateral gene transfer may have contributed to the ability of strain $\mathrm{P} 73^{\mathrm{T}}$ to catabolize aromatic compounds. Notably, region B of the genome, which contained the PAH-degrading genes and were absent in another bacterium of Celeribacter, strain B30, was predicted to have been acquired via lateral gene transfer. This study will provide a molecular basis for future research into the functions of the $\mathrm{P} 73^{\mathrm{T}}$ genes.

Aromatic ring hydroxylation is the most difficult catalytic step of fluoranthene degradation. Several dioxygenases that can transform fluoranthene have been reported previously, including ArhA1 [GenBank:BAD34447] ${ }^{55}$, PhnAla [GenBank:CAG17576] ${ }^{56}$, PhnAlf [GenBank:ABW37061] ${ }^{57}$ NidA3 [GenBank:ABM11369] ${ }^{2}$, PhdA [GenBank:ABK27720] ${ }^{58}$, CarAa [GenBank:BAA21728 $]^{59}$, Mvan_0533 [GenBank:ABM11377] and Mvan_0539 [GenBank:ABM11383]2, FlnA1 [GenBank:ABV68886] ${ }^{60}$, and IdoA (GenBank:AF474963) ${ }^{61}$. However, none of these belong to the toluene/biphenyl family (group IV). The P73_0346 gene represents the first identified fluoranthene 7,8-dioxygenase and the first toluene/biphenyl family fluoranthene dioxygenase to be reported. P73_0346 is also responsible for the dioxygenation of naphthalene, biphenyl, phenanthrene and dibenzothiophene, which are structurally similar to fluoranthene.

The proposed C-7,8 dioxygenation pathway for fluoranthene metabolism in strain $\mathrm{P} 73^{\mathrm{T}}$ is consistent with the pathway that involved extradiol cleavage of 7,8-dihydroxyfluoranthene reported previously ${ }^{2,18}$. However, the C-7,8 dioxygenation pathway was the only pathway detected in strain $\mathrm{P} 73^{\mathrm{T}}$, in contrast to other bacteria, which typically have two or more different pathways for fluoranthene metabolism ${ }^{25,17,18}$. Therefore, strain $\mathrm{P}^{2} 3^{\mathrm{T}}$, the first fluoranthene-degrading Rhodobacteraceae bacterium reported, may be a useful strain in which the C-7,8 dioxygenation pathway involving extradiol cleavage of 7,8-dihydroxyfluoranthene can be studied. Further, $\mathrm{P} 73^{\mathrm{T}}$ is a novel $\mathrm{PAH}$-degrading bacterium that may have the potential to be applied in marine oil spill bioremediation.

Although this study presents the genomic complement of PAH degradation and the fluoranthene degradative pathway in strain $\mathrm{P}^{\mathrm{T}}{ }^{\mathrm{T}}$, finding out the complete physiology of the bacterium towards $\mathrm{PAH}$ degradation still demands more explorations. Additional experiment is necessary to study the functions of catabolic gene as well as the mechanisms of regulation and transportation in strain $\mathrm{P}^{7} 3^{\mathrm{T}}$ with respect to $\mathrm{PAH}$ degradation. It is also interesting to study the role of the five plasmids in the PAH metabolism.

\section{Methods}

Bacterial growth and DNA extraction. C. indicus $\mathrm{P} 73^{\mathrm{T}}$, isolated from deep-sea sediment of the Indian Ocean, and C. baekdonensis B30, isolated from deep-sea sediment of the Arctic Ocean, were grown on $216 \mathrm{~L}$ agar medium at $28^{\circ} \mathrm{C}^{23}$. Genomic DNA was extracted according to the method of Ausubel et al. ${ }^{68}$.
Genome sequencing and analysis. The sequencing of the $\mathrm{P} 73^{\mathrm{T}}$ and $\mathrm{B} 30$ genomes was carried out at the Beijing Genomics Institute (BGI; Shenzhen, China) using Solexa paired-end sequencing technology ${ }^{69}$. Gaps between the assembled $\mathrm{P} 73^{\mathrm{T}}$ scaffolds were filled by generating PCR products and sequencing them using an ABI 3730 capillary sequencer (Applied Biosystems, Foster City, CA).

Protein coding sequences were predicted using Glimmer $3.0^{70}$. The genomic analyses were performed as described previously ${ }^{71}$ using the tools available on the Integrated Microbial Genomes (IMG) server (https://img.jgi.doe.gov) ${ }^{42}$. Genomic islands (GIs) were analyzed using IslandViewer (http://www.pathogenomics.sfu.ca/ islandviewer $)^{29}$

Mutant generation. A gene deletion $\mathrm{P} 73^{\mathrm{T}}$ mutant was generated using of the cre-lox recombination method reported by Marx and Lidstrom ${ }^{72}$. Escherichia coli WM3064 was used as the conjugal donor strain, and pJK100 (allelic-exchange vector, $\mathrm{Tc}^{\mathrm{R}}, \mathrm{Km}^{\mathrm{R}}$ ) was used as the suicide vector ${ }^{73}$. More information on all aspects of the mutant generation method can be found in the Supplementary Text S7.

Analysis of intermediate metabolites in fluoranthene degradation. Strain $\mathrm{P} 73^{\mathrm{T}}$ was grown in artificial sea water (ASM) medium ${ }^{74}$ supplemented with fluoranthene $(20 \mathrm{mg} / \mathrm{L})$ as the sole source of carbon and energy at $28^{\circ} \mathrm{C}$ and $160 \mathrm{rpm}$. Metabolites were extracted and processed for analysis as described previously ${ }^{4,5}$ with slight modification (see Supplementary Text S8 for details). After silylation with $N, O-$ bis(trimethylsilyl)-trifluoroacetamide with $1 \%$ trimethylchlorosilane, the samples were analyzed by GC-MS (QP2010, Shimadzu, Kyoto, Japan) in the SCAN mode. Metabolites were determined based on the molecular and fragment ions in the mass spectra and the chromatographic retention time $\left(R_{t}\right)$ of authentic compounds.

1. Kanaly, R. \& Harayama, S. Biodegradation of high-molecular-weight polycyclic aromatic hydrocarbons by bacteria. J. Bacteriol. 182, 2059-2067 (2000).

2. Kweon, O. et al. Polycyclic Aromatic Hydrocarbon Metabolic Network in Mycobacterium vanbaalenii PYR-1. J. Bacteriol. 193, 4326-4337 (2011).

3. Fuchs, G., Boll, M. \& Heider, J. Microbial degradation of aromatic compounds from one strategy to four. Nat. Rev. Microbiol. 9, 803-816 (2011).

4. Kweon, O. et al. A polyomic approach to elucidate the fluoranthene-degradative pathway in Mycobacterium vanbaalenii PYR-1. J. Bacteriol. 189, 4635-4647 (2007).

5. Lee, S. E., Seo, J. S., Keum, Y. S., Lee, K. J. \& Li, Q. X. Fluoranthene metabolism and associated proteins in Mycobacterium sp. JS14. Proteomics 7, 2059-2069 (2007).

6. Keum, Y. S., Seo, J. S., Hu, Y. \& Li, Q. X. Degradation pathways of phenanthrene by Sinorhizobium sp. C4. Appl. Microbiol. Biotechnol. 71, 935-941 (2006).

7. van Herwijnen, R. et al. Elucidation of the metabolic pathway of fluorene and cometabolic pathways of phenanthrene, fluoranthene, anthracene and dibenzothiophene by Sphingomonas sp. LB126. Res. Microbiol. 154, 199-206 (2003).

8. Akhtar, N., Ghauri, M. A., Anwar, M. A. \& Akhtar, K. Analysis of the dibenzothiophene metabolic pathway in a newly isolated Rhodococcus spp. FEMS Microbiol. Lett. 301, 95-102 (2009).

9. Šepič, E., Bricelj, M. \& Leskovsek, H. Degradation of fluoranthene by Pasteurella sp. IFA and Mycobacterium sp. PYR-1:isolation and identification of metabolites. J. Appl. Microbiol. 85, 746-754 (1998).

10. Mallick, S., Chatterjee, S. \& Dutta, T. K. A novel degradation pathway in the assimilation of phenanthrene by Staphylococcus sp strain PN/Y via meta-cleavage of 2-hydroxy-1-naphthoic acid: formation of trans-2,3-dioxo-5-(2' hydroxyphenyl)pent-4-enoic acid. Microbiology 153, 2104-2115 (2007).

11. Marx, C. J., Miller, J. A., Chistoserdova, L. \& Lidstrom, M. E. Multiple formaldehyde oxidation/detoxification pathways in Burkholderia fungorum LB400. J. Bacteriol. 186, 2173-2178 (2004).

12. Prabhu, Y. \& Phale, P. S. Biodegradation of phenanthrene by Pseudomonas sp. strain PP2: novel metabolic pathway, role of biosurfactant and cell surface hydrophobicity in hydrocarbon assimilation. Appl. Microbiol. Biotechnol. 61, 342-351 (2003)

13. Baboshin, M. et al. Conversion of polycyclic aromatic hydrocarbons by Sphingomonas sp. VKM B-2434. Biodegradation 19, 567-576 (2008).

14. Weissenfels, W. D., Beyer, M. \& Klein, J. Degradation of phenanthrene, fluorene and fluoranthene by pure bacterial cultures. Appl. Microbiol. Biotechnol. 32, 479-484 (1990).

15. Juhasz, A. L., Britz, M. L. \& Stanley, G. A. Degradation of fluoranthene, pyrene, benz $[a]$ anthracene and dibenz $[a, h]$ anthracene by Burkholderia cepacia. J. Appl. Microbiol. 83, 189-198 (1997).

16. Gordon, L. \& Dobson, A. D. Fluoranthene degradation in Pseudomonas alcaligenes PA-10. Biodegradation 12, 393-400 (2001).

17. Rehmann, K., Hertkorn, N. \& Kettrup, A. A. Fluoranthene metabolism in Mycobacterium sp. strain KR20: identity of pathway intermediates during degradation and growth. Microbiology 147, 2783-2794 (2001).

18. López, Z., Vila, J., Minguillón, C. \& Grifoll, M. Metabolism of fluoranthene by Mycobacterium sp. strain AP1. Appl. Microbiol. Biotechnol. 70, 747-756 (2006)

19. Walter, U., Beyer, M., Klein, J. \& Rehm, H.-J. Degradation of pyrene by Rhodococcus sp. UW1. Appl. Microbiol. Biotechnol. 34, 671-676 (1991).

20. Wu, Y. R. et al. Isolation of marine benzo[a]pyrene-degrading Ochrobactrum sp. BAP5 and proteins characterization. J. Environ. Sci. (China) 21, 1446-1451 (2009). 
21. Yuan, J., Lai, Q., Zheng, T. \& Shao, Z. Novosphingobium indicum sp. nov., a polycyclic aromatic hydrocarbon-degrading bacterium isolated from a deep-sea environment. Int. J. Syst. Evol. Microbiol. 59, 2084-2088 (2009).

22. Geiselbrecht, A. D., Hedlund, B. P., Tichi, M. A. \& Staley, J. T. Isolation of marine polycyclic aromatic hydrocarbon (PAH)-degrading Cycloclasticus strains from the Gulf of Mexico and comparison of their PAH degradation ability with that of Puget Sound Cycloclasticus strains. Appl. Environ. Microbiol. 64, 4703-4710 (1998).

23. Lai, Q., Cao, J., Yuan, J., Li, F. \& Shao, Z. Celeribacter indicus sp. nov. a polycyclic aromatic hydrocarbon-degrading bacterium from deep-sea sediment and reclassification of Huaishuia halophila as Celeribacter halophilus comb. nov. Int. J. Syst. Evol. Microbiol. 64, 4160-4167 (2014).

24. Weissenfels, W., Beyer, M., Klein, J. \& Rehm, H. Microbial metabolism of fluoranthene: isolation and identification of ring fission products. Appl. Microbiol. Biotechnol. 34, 528-535 (1991).

25. Kim, S. J., Kweon, O., Jones, R. C., Edmondson, R. D. \& Cerniglia, C. E. Genomic analysis of polycyclic aromatic hydrocarbon degradation in Mycobacterium vanbaalenii PYR-1. Biodegradation 19, 859-881 (2008).

26. Hickey, W. J., Chen, S. \& Zhao, J. The phn Island: A New Genomic Island Encoding Catabolism of Polynuclear Aromatic Hydrocarbons. Front. microbiol. 3, 125 (2012).

27. Math, R. K. et al. Comparative genomics reveals adaptation by Alteromonas $\mathrm{sp}$. $\mathrm{SN} 2$ to marine tidal-flat conditions: cold tolerance and aromatic hydrocarbon metabolism. PLoS ONE 7, e35784 (2012).

28. Yagi, J. M., Sims, D., Brettin, T., Bruce, D. \& Madsen, E. L. The genome of Polaromonas naphthalenivorans strain CJ2, isolated from coal tarcontaminated sediment, reveals physiological and metabolic versatility and evolution through extensive horizontal gene transfer. Environ. Microbiol. 11, 2253-2270 (2009).

29. Langille, M. G. \& Brinkman, F. S. IslandViewer: an integrated interface for computational identification and visualization of genomic islands. Bioinformatics 25, 664-665 (2009).

30. Beales, N. Adaptation of microorganisms to cold temperatures, weak acid preservatives, low $\mathrm{pH}$, and osmotic stress: a review. Compr. Rev. Food Sci. Food Saf. 3, 1-20 (2004)

31. Saier, M. H., Jr., Yen, M. R., Noto, K., Tamang, D. G. \& Elkan, C. The Transporter Classification Database: recent advances. Nucleic Acids Res. 37, D274-278 (2009).

32. Davidson, A. L., Dassa, E., Orelle, C. \& Chen, J. Structure, function, and evolution of bacterial ATP-binding cassette systems. Microbiol. Mol. Biol. Rev. 72, 317-364 (2008).

33. Chang, H. K., Dennis, J. J. \& Zylstra, G. J. Involvement of two transport systems and a specific porin in the uptake of phthalate by Burkholderia spp. J. Bacteriol. 191, 4671-4673 (2009).

34. Mulligan, C., Fischer, M. \& Thomas, G. H. Tripartite ATP-independent periplasmic (TRAP) transporters in bacteria and archaea. FEMS Microbiol. Rev. 35, 68-86 (2011)

35. Chaudhry, M. T. et al. Genome-wide investigation of aromatic acid transporters in Corynebacterium glutamicum. Microbiology 153, 857-865 (2007).

36. Hosaka, M. et al. Novel tripartite aromatic acid transporter essential for terephthalate uptake in Comamonas sp. strain E6. Appl. Environ. Microbiol. 79, 6148-6155 (2013)

37. Kahng, H. Y., Byrne, A. M., Olsen, R. H. \& Kukor, J. J. Characterization and role of tbuX in utilization of toluene by Ralstonia pickettii PKO1. J. Bacteriol. 182, 1232-1242 (2000).

38. Maddocks, S. E. \& Oyston, P. C. Structure and function of the LysR-type transcriptional regulator (LTTR) family proteins. Microbiology 154, 3609-3623 (2008).

39. Tropel, D. \& van der Meer, J. R. Bacterial transcriptional regulators for degradation pathways of aromatic compounds. Microbiol. Mol. Biol. Rev. 68 , 474-500 (2004).

40. Molina-Henares, A. J., Krell, T., Eugenia Guazzaroni, M., Segura, A. \& Ramos, J. L. Members of the IclR family of bacterial transcriptional regulators function as activators and/or repressors. FEMS Microbiol. Rev. 30, 157-186 (2006).

41. Mazur, A., Majewska, B., Stasiak, G., Wielbo, J. \& Skorupska, A. repABC-based replication systems of Rhizobium leguminosarum bv. trifolii TA1 plasmids: incompatibility and evolutionary analyses. Plasmid 66, 53-66 (2011).

42. Markowitz, V. M. et al. The integrated microbial genomes system: an expanding comparative analysis resource. Nucleic Acids Res. 38, D382-390 (2010).

43. Kuyukina, M. S. \& Ivshina, I. B. in Biology of Rhodococcus Vol. 16 Microbiology Monographs (ed Héctor M. Alvarez) Ch. Rhodococcus Biosurfactants: Biosynthesis, Properties, and Potential Applications, 291-313 (Springer, 2010).

44. Himmelreich, R. et al. Complete sequence analysis of the genome of the bacterium Mycoplasma pneumoniae. Nucleic Acids Res. 24, 4420-4449 (1996).

45. Velasco-Casal, P., Wick, L. Y. \& Ortega-Calvo, J. J. Chemoeffectors decrease the deposition of chemotactic bacteria during transport in porous media. Environ. Sci. Technol. 42, 1131-1137 (2008).

46. Nie, Y.et al. The genome sequence of Polymorphum gilvum SL003B-26A1 ${ }^{\mathrm{T}}$ reveals its genetic basis for crude oil degradation and adaptation to the saline soil. PLoS ONE 7, e31261 (2012).
47. Kim, J. S., Chang, J. H., Chung, S. I. \& Yum, J. S. Molecular cloning and characterization of the Helicobacter pylori fliD gene, an essential factor in flagellar structure and motility. J. Bacteriol. 181, 6969-6976 (1999).

48. Mukherjee, S., Babitzke, P. \& Kearns, D. B. FliW and FliS function independently to control cytoplasmic flagellin levels in Bacillus subtilis. J. Bacteriol. 195, 297-306 (2013).

49. Wilkinson, D. A., Chacko, S. J., Venien-Bryan, C., Wadhams, G. H. \& Armitage, J. P. Regulation of flagellum number by FliA and FlgM and role in biofilm formation by Rhodobacter sphaeroides. J. Bacteriol. 193, 4010-4014 (2011).

50. Macnab, R. M. Type III flagellar protein export and flagellar assembly. Biochim. Biophys. Acta 1694, 207-217 (2004).

51. Pilsl, H., Smajs, D. \& Braun, V. Characterization of colicin S4 and its receptor, OmpW, a minor protein of the Escherichia coli outer membrane. J. Bacteriol. 181, 3578-3581 (1999).

52. Hacker, J., Blum-Oehler, G., Muhldorfer, I. \& Tschape, H. Pathogenicity islands of virulent bacteria: structure, function and impact on microbial evolution. Mol. Microbiol. 23, 1089-1097 (1997).

53. van den Berg, B., Black, P. N., Clemons, W. M., Jr. \& Rapoport, T. A. Crystal structure of the long-chain fatty acid transporter FadL. Science 304, 1506-1509 (2004).

54. Parales, R. E. \& Resnick, S. M. Aromatic ring hydroxylating dioxygenases. Pseudomonas 4, 287-340 (2006).

55. Pinyakong, O. et al. Isolation and characterization of genes encoding polycyclic aromatic hydrocarbon dioxygenase from acenaphthene and acenaphthylene degrading Sphingomonas sp. strain A4. FEMS Microbiol. Lett. 238, 297-305 (2004).

56. Jouanneau, Y., Meyer, C., Jakoncic, J., Stojanoff, V. \& Gaillard, J. Characterization of a naphthalene dioxygenase endowed with an exceptionally broad substrate specificity toward polycyclic aromatic hydrocarbons. Biochemistry 45, 12380-12391 (2006).

57. Schuler, L. et al. Characterization of a ring-hydroxylating dioxygenase from phenanthrene-degrading Sphingomonas sp. strain LH128 able to oxidize benz[a]anthracene. Appl. Microbiol. Biotechnol. 83, 465-475 (2009).

58. Pagnout, C. et al. Isolation and characterization of a gene cluster involved in $\mathrm{PAH}$ degradation in Mycobacterium sp. strain SNP11: Expression in Mycobacterium smegmatis $\mathrm{mc}^{2} 155$. Res. Microbiol. 158, 175-186 (2007).

59. Nojiri, H. et al. Diverse oxygenations catalyzed by carbazole 1,9a-dioxygenase from Pseudomonas sp. Strain CA10. J. Bacteriol. 181, 3105-3113 (1999).

60. Schuler, L. et al. Characterization of a novel angular dioxygenase from fluorenedegrading Spingomonas sp. strain LB126. Appl. Environ. Microbiol. 74, 1050-1057 (2008).

61. Alemayehu, D., Gordon, L. M., O’Mahony, M. M., O’Leary, N. D. \& Dobson, A. D. Cloning and functional analysis by gene disruption of a novel gene involved in indigo production and fluoranthene metabolism in Pseudomonas alcaligenes PA10. FEMS Microbiol. Lett. 239, 285-293 (2004).

62. Thompson, L. C. et al. 2-Hydroxychromene-2-carboxylic acid isomerase: a kappa class glutathione transferase from Pseudomonas putida. Biochemistry 46, 6710-6722 (2007).

63. Keck, A. et al. Identification and functional analysis of the genes for naphthalenesulfonate catabolism by Sphingomonas xenophaga BN6. Microbiology 152, 1929-1940 (2006).

64. Liu, T. T. et al. Functional characterization of a gene cluster involved in gentisate catabolism in Rhodococcus sp. strain NCIMB 12038. Appl. Microbiol. Biotechnol. 90, 671-678 (2011)

65. Brzostowicz, P. C., Reams, A. B., Clark, T. J. \& Neidle, E. L. Transcriptional cross-regulation of the catechol and protocatechuate branches of the betaketoadipate pathway contributes to carbon source-dependent expression of the Acinetobacter sp strain ADP1 pobA gene. Appl. Environ. Microbiol. 69, 1598-1606 (2003).

66. Arias-Barrau, E. et al. The homogentisate pathway: a central catabolic pathway involved in the degradation of L-phenylalanine, L-tyrosine, and 3hydroxyphenylacetate in Pseudomonas putida. J. Bacteriol. 186, 5062-5077 (2004).

67. Lee, S. Y., Park, S., Oh, T. K. \& Yoon, J. H. Celeribacter baekdonensis sp. nov. isolated from seawater, and emended description of the genus Celeribacter Ivanova et al. 2010. Int. J. Syst. Evol. Microbiol. 62, 1359-1364 (2012).

68. Ausubel, F. M. et al. Short Protocols in Molecular Biology: A Compendium of Methods from Current Protocols in Molecular Biology (Wiley, New York, 2002).

69. Bentley, D. R. et al. Accurate whole human genome sequencing using reversible terminator chemistry. Nature 456, 53-59 (2008).

70. Delcher, A. L., Bratke, K. A., Powers, E. C. \& Salzberg, S. L. Identifying bacterial genes and endosymbiont DNA with Glimmer. Bioinformatics 23, 673-679 (2007)

71. Fukao, M. et al. Genomic analysis by deep sequencing of the probiotic Lactobacillus brevis KB290 harboring nine plasmids reveals genomic stability. PLoS ONE 8, e60521 (2013).

72. Marx, C. J. \& Lidstrom, M. E. Broad-host-range cre-lox system for antibiotic marker recycling in gram-negative bacteria. Biotechniques 33, 1062-1067 (2002)

73. Denef, V. J. et al. Genetic and genomic insights into the role of benzoate-catabolic pathway redundancy in Burkholderia xenovorans LB400. Appl. Environ. Microbiol. 72, 585-595 (2006). 
74. Liu, C. \& Shao, Z. Alcanivorax dieselolei sp. nov., a novel alkane-degrading bacterium isolated from sea water and deep-sea sediment. Int. J. Syst. Evol. Microbiol. 55, 1181-1186 (2005).

\section{Acknowledgments}

This work was financially supported by COMRA program (No. DY125-15-R-01), Public Welfare Project of SOA (201005032), National Natural Science Foundation of China (41176154/41276005) and National Infrastructure of Microbial Resources of China (No. NIMR-2014-9). We thank Dr. Shicheng CHEN for providing us strain Escherichia coli WM3064 and plasmid pJK100, and thank Dr. Mohamed JEBBAR for critical reading of this manuscript.

\section{Author contributions}

Z.S. conceived the project and supervised the genomic and bioinformatics studies. J.C., Q.L., J.Y. and Z.S. performed the experiments and analyzed the data. J.C., Q.L. and Z.S. wrote the paper

\section{Additional information}

Accession codes: The sequences of the six replicons of strain $\mathrm{P} 73^{\mathrm{T}}$ have been deposited in GenBank (Accession: CP004393 - CP004398). The whole genome shotgun sequence of strain B30 is also available (Accession: AMRK00000000).

Supplementary information accompanies this paper at http://www.nature.com/ scientificreports

Competing financial interests: The authors declare no competing financial interests.

How to cite this article: Cao, J., Lai, Q., Yuan, J. \& Shao, Z. Genomic and metabolic analysis of fluoranthene degradation pathway in Celeribacter indicus $\mathrm{P}^{\mathrm{T}} 3^{\mathrm{T}}$. Sci. Rep. 5, 7741; DOI:10.1038/srep07741 (2015).

(c) (1) (2) (2) This work is licensed under a Creative Commons Attribution-NonCommercialShareAlike 4.0 International License. The images or other third party material in this article are included in the article's Creative Commons license, unless indicated otherwise in the credit line; if the material is not included under the Creative Commons license, users will need to obtain permission from the license holder in order to reproduce the material. To view a copy of this license, visit http:// creativecommons.org/licenses/by-nc-sa/4.0/ 